\title{
Genes involved in translation of Mycoplasma hyopneumoniae and Mycoplasma synoviae
}

\author{
Mônica de Oliveira Santos, Nadya da Silva Castro, Maristela Pereira and Célia Maria de Almeida Soares \\ Laboratório de Biologia Molecular, Instituto de Ciências Biológicas, Universidade Federal de Goiás, \\ Goiânia, Goiás, Brazil.
}

\begin{abstract}
This is a report on the analysis of genes involved in translation of the complete genomes of Mycoplasma hyopneumoniae strain $\mathrm{J}$ and 7448 and Mycoplasma synoviae. In both genomes 31 ORFs encoding large ribosomal subunit proteins and 19 ORFs encoding small ribosomal subunit proteins were found. Ten ribosomal protein gene clusters encoding 42 ribosomal proteins were found in M. synoviae, while 8 clusters encoding 39 ribosomal proteins were found in both $M$. hyopneumoniae strains. The L33 gene of the M. hyopneumoniae strain 7448 presented two copies in different locations. The genes encoding initiation factors (IF-1, IF-2 and IF-3), elongation factors (EF-G, EF-Tu, EF-Ts and EF-P), and the genes encoding the ribosome recycling factor (frr) and one polypeptide release factor $(p r f A)$ were present in the genomes of $M$. hyopneumoniae and $M$. synoviae. Nineteen aminoacyl-tRNA synthases had been previously identified in both mycoplasmas. In the two strains of $M$. hyopneumoniae, J and 7448, only one set of 5S, $16 \mathrm{~S}$ and $23 \mathrm{~S}$ rRNAs had been identified. Two sets of $16 \mathrm{~S}$ and $23 \mathrm{~S}$ rRNA genes and three sets of $5 S$ rRNA genes had been identified in the M. synoviae genome.
\end{abstract}

Key words: mycoplasmas, Mycoplasma synoviae, Mycoplasma hyopneumoniae, translation, genome.

Received: April 12, 2006; Accepted: October 5, 2006.

\section{Introduction}

Mycoplasmas comprise a very large group of prokaryotes widely distributed in nature as parasites and pathogens of humans, animals, plants and insects (Razin, 1992). Because mycoplasmas have an extremely small genome (0.58-2.20 Mb compared to the 4.64 Mb of Escherichia coli), these organisms have limited metabolic options for replication and survival (Maniloff, 1996).

Mycoplasma-induced arthritis of poultry is almost entirely caused by Mycoplasma synoviae infection, which is present on poultry farms all over the world, either sporadically or endemically (Jordan, 1981; Bencina et al., 1999). Infection most frequently occurs as a subclinical respiratory tract infection, which can progress to respiratory disease or to infectious synovitis, in which the synovial membranes of joint and tendon sheaths are affected. Under so far unknown conditions, the $M$. synoviae disease can become systemic, causing systemic vasculitis and pathological changes in numerous organs. Porcine enzootic pneumonia, with M. hyopneumoniae as the primary agent,

Send correspondence to Célia Maria de Almeida Soares. Laboratório de Biologia Molecular, Instituto de Ciências Biológicas, Universidade Federal de Goiás, 74001-970 Goiânia, Goiás, Brazil. E-mail: celia@ icb.ufg.br. is a chronic respiratory disease present in the vast majority of swine farms worldwide, that causes respiratory distress resulting from pneumonia in growing pigs (Kobisch and Friis, 1996; Kobisch, 2000).

Translation is a key step in gene expression, converting the genetic information encoded in messenger RNAs (mRNAs) into contiguous chains of amino acids with structural and/or catalytic properties (Lafontaine and Tollervey, 2001). In this work, we analyzed several aspects of the translation machineries by searching the genes involved in translation of $M$. hyopneumoniae strain $\mathrm{J}, M$. hyopneumoniae strain 7448 , and M. synoviae in the Mycoplasma database and by comparing the results to Mycoplasma and other genomes.

\section{Methods}

Genes involved in translation of $M$. hyopneumoniae strains $\mathrm{J}$ and 7448 and $M$. synoviae where retrieved in the Mycoplasma database. Annotation data were used to compare the gene organization among the three mycoplasmas and to the E. coli and Corynebacterium glutamicum models (Martín et al., 2003). The translated amino acid sequences of $\mathrm{L} 33$ ribosomal and gat (A, B and C) proteins were retrieved from the database and used to search for related sequences by using BLAST tools (Altschul et al., 1997). 
Seventeen and twenty-two amino acid sequences of L33 and gat proteins, respectively, were used to construct phylogenetic trees by multiple sequence alignments, using the Clustal X program, version 1.8 (Thompson et al., 1997) and the neighbor-joining method (Saitou and Nei, 1987). Robustness of branches was estimated using 100-bootstrap replicates. The amino acid sequences were visualized using the TreeView software.

\section{Results and Discussion}

\section{Genes encoding ribosomal proteins}

The amino acid sequences of the ribosomal proteins of $M$. synoviae, $M$. hyopneumoniae strain $\mathrm{J}$, and $M$. hyopneumoniae strain 7448 have been deduced from the genome sequence (Vasconcelos et al., 2005). Thirty-one ORFs (Open Reading Frames) encoding large ribosomal subunit proteins, and 19 ORFs encoding small ribosomal subunit proteins were found in the genomes of M. synoviae,
M. hyopneumoniae $\mathrm{J}$ and $M$. hyopneumoniae 7448 , as shown in Table 1.

Those ribosomal protein families including L1-L6, L9-L24, L27-L29 and L31-36, as well as S2 to S20, correspond to the stable pool of 50 ribosomal proteins described in bacteria. S1, S21, L25 and L30 are the only four wellestablished bacterial ribosomal proteins which exhibit a disparate distribution (Lecompte et al., 2002). Those four genes were not found in the three mycoplasma genomes sequenced. Among the mycoplasmas, the $\mathrm{S} 1$ protein was also absent in the genomes of $M$. genitalium and $M$. pneumoniae, but has been identified in M. pulmonis (GenBank accession number: Q98R80). The S21 gene has been identified in the genomes of $M$. gallisepticum, $M$. genitalium, M. penetrans, M. pneumoniae and Ureaplasma urealyticum (Lecompte et al., 2002).

Many of the ribosomal proteins have been shown to be crucial for ribosome assembly, such as the early assembling proteins S4p, S7p, S8p, S15p, S17p, L2p, L3p, L4p, L5p, L15p, L18p (Held et al., 1974; Rohl and Nierhaus,

Table 1 - Genes encoding ribosomal proteins identified in the genomes of M. synoviae, M. hyopmeumoniae J, and M. hyopneumoniae 7448.

\begin{tabular}{|c|c|c|c|c|c|c|c|}
\hline Product & $\begin{array}{l}\text { ORF } M . \\
\text { synoviae }\end{array}$ & $\begin{array}{l}\text { ORF M. hyo- } \\
\text { pneumoniae } \mathrm{J}\end{array}$ & $\begin{array}{c}\text { ORF M. hyo- } \\
\text { pneumoniae } 7448\end{array}$ & Product & $\begin{array}{l}\text { ORF M. } \\
\text { synoviae }\end{array}$ & $\begin{array}{l}\text { ORF M. hyo- } \\
\text { pneumoniae J }\end{array}$ & $\begin{array}{c}\text { ORF M. hyo- } \\
\text { pneumoniae } 7448\end{array}$ \\
\hline \multicolumn{4}{|c|}{ Ribosomal large subunit } & L31 & MS06767 & MH14988 & MP07171 \\
\hline L1 & MS00507 & MH10385 & MP01569 & L32 & MS06893 & MH10338 & MP07170 \\
\hline L2 & MS00378 & MH02612 & MP04292 & L33 & MS06951 & MH10377 & MP12668/MP12594 \\
\hline L3 & MS00334 & МH02630 & MP04310 & L34 & MS06957 & МH04919 & МР07097 \\
\hline L4 & MS00343 & MH15027 & MP04305 & L35 & MS06887 & MH10352 & MP07167 \\
\hline L5 & MS00437 & MH02516 & MP12664 & L36 & MS06935 & MH10380 & MP07166 \\
\hline L6 & MS00450 & MH02493 & MP04205 & \multicolumn{4}{|c|}{ Ribosomal small subunit } \\
\hline L7/L12 & MS02743 & MH01479 & MH01479 & $\mathrm{S} 2$ & MS02838 & MH04101 & MP12674 \\
\hline L9 & MS02675 & MH10381 & MP03703 & S3 & MS00405 & MH10344 & MP04271 \\
\hline L10 & MS02747 & MH01488 & MP12655 & S4 & MS02216 & MH04390 & MP12704 \\
\hline L11 & MS12947 & MH19654 & MP18913 & S5 & MS06783 & МH02490 & MP04182 \\
\hline L13 & MS05775 & MH05352 & MP03756 & S6 & MS01398 & MH01222 & МР07141 \\
\hline L14 & MS06954 & MH02527 & MP04228 & S7 & MS06010 & MH03876 & MP05936 \\
\hline L15 & MS00485 & МH02489 & MP04181 & S8 & MS06885 & MH10396 & MP07133 \\
\hline L16 & MS00409 & MH02573 & MP12667 & S9 & MS06897 & MH05346 & MP03749 \\
\hline L17 & MS06953 & MH10382 & МР00474 & S10 & MS06955 & MH10370 & MP12640 \\
\hline L18 & MS06886 & MH15043 & MP07134 & S11 & MS06958 & MH10341 & МР00487 \\
\hline L19 & MS06900 & MH10337 & MP07138 & S12 & MS05989 & MH10388 & MP05913 \\
\hline L20 & MS00655 & MH10351 & MP07168 & S13 & MS00910 & MH02418 & МР00493 \\
\hline L21 & MS06883 & MH09954 & MP02359 & S14 & MS06952 & MH10364 & MP07130 \\
\hline L22 & MS06928 & MH02596 & MP12665 & S15 & MS06949 & MH10387 & MP07135 \\
\hline L23 & MS00356 & МH02615 & MP04295 & S16 & MS13161 & MH10336 & МР07137 \\
\hline L24 & MS06929 & MH02520 & MP04222 & S17 & MS00414 & MH02540 & MP12523 \\
\hline L27 & MS01224 & MH09955 & MP10612 & $\mathrm{S} 18$ & MS01383 & MH10335 & MP12686 \\
\hline L28 & MS06941 & MH10386 & MP07143 & S19 & MS00392 & MH15042 & MP07132 \\
\hline L29 & MS00411 & MH10365 & MP07165 & $\mathrm{S} 20$ & MS06926 & MH15044 & MP07163 \\
\hline
\end{tabular}




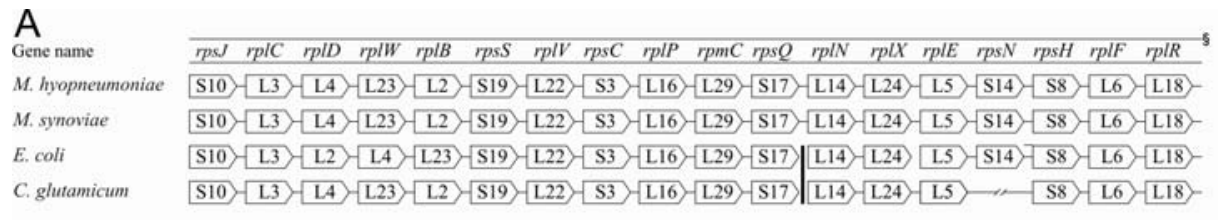

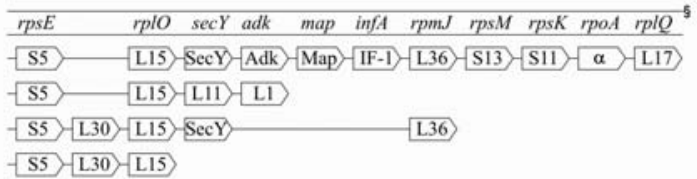

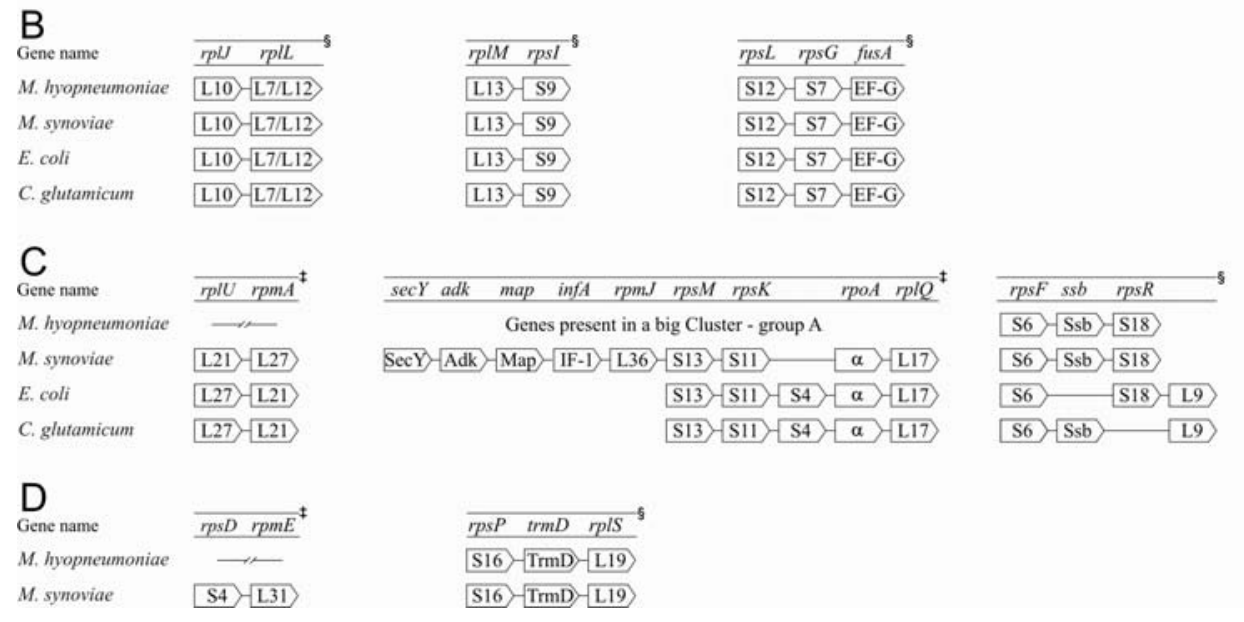

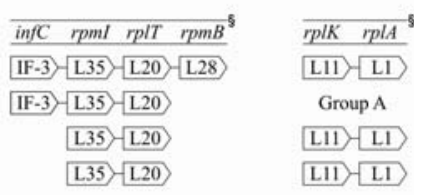

Figure 1 - Gene clusters of ribosomal proteins in Mycoplasma synoviae, Mycoplasma hyopneumoniae, Escherichia coli and Corynebacterium glutamicum. Arrows represent genes with their relative orientation in the genomes. Contiguous arrows represent adjacent genes, while interrupted lines indicate loss of proximity. The solid bar indicates the limit of the S10 and spc operons in E. coli and C. glutamicum. The names of the genes were obtained from $M$. hyopneumoniae ( $($ ) or from $M$. synoviae (\$) (when the name was not defined for $M$. hyopneumoniae). (A) A big cluster showing differences between the four organisms; (B) Clusters with identical organization in the four organisms; (C) Another cluster showing differences between the organisms; (D) Clusters presenting particularities in $M$. synoviae and $M$. hyopneumoniae. Abbreviations used for gene names: SecY (preprotein translocase secY subunit), Adk (adenylate kinase), Map (methionyl aminopeptidase), IF-1 (translation initiation factor IF-1), $\alpha$ (DNA-directed RNA polymerase subunit alpha), EF-G (elongation factor EF-G), Ssb (single-stranded DNA-binding protein), IF-3 (translation initiation factor IF-3), TrmD (tRNA (guanine-N1)-methyltransferase). Data for E. coli and C. glutamicum were retrieved from NCBI's complete genome section and from Martín et al. (2003).

1982), and some have been implicated in the formation of bridges between the two subunits (S13p, S15p, S19p, L2p, L5p, L14p) (Yusupov et al., 2001). Binding of ribosomes to mRNA involves the ribosomal proteins S1, S3, S4, S5, S9, $\mathrm{S} 12$ and S18, in addition to the 16S rRNA (Stern et al., 1988). Proteins L2, L11, L15, L16, L18, L23 and L27, together with the 23S rRNA, are involved in the peptidyl transferase function of ribosomes (Voet and Voet, 1992). The four proteins L7/L12 form a protruding domain of the large subunit that participates in the GTPase activity of ribosomes (Uchiumi et al., 2002). Other proteins, such as S7p, S9p, S12p, S13p, L1p and L5p, are in contact with the tRNA or surround the polypeptide exit channel (L22p, L24p and L29p) (Yusupov et al., 2001).

\section{Organization of gene clusters encoding ribosomal proteins}

Most genes encoding ribosomal proteins are clustered forming operons. In the three sequenced genomes, we found 10 ribosomal protein gene clusters encoding 42 ribo- somal proteins in $M$. synoviae, and 8 clusters encoding 39 ribosomal proteins in both $M$. hyopneumoniae strains, as shown in Figure 1. In the E. coli and C. glutamicum models (Martín et al., 2003), there are 11 gene clusters encoding 41 and 42 ribosomal proteins, respectively. In E. coli, the S10 operon encodes 11 ribosomal proteins in the following order: S10, L3, L2, L4, L23, S19, L22, S3, L16, L29 and S17, and is located close to the $s p c$ operon that includes 12 genes which encode the proteins L14, L24, L5, S14, S8, L6, L18, S5, L30, L15, Sec Y and L36 (Cerretti et al., 1983). These two operons correspond in organization to the big cluster in M. hyopneumoniae and M. synoviae with minor differences, as shown in Figure 1A. In M. hyopneumoniae, the large block of approximately $15 \mathrm{~kb}$ contains 29 genes, 24 of which encode ribosomal proteins. This block of genes also contains those encoding the SecY subunit of the preprotein translocase ( $\sec Y)$, adenylate kinase $(a d k)$, methionine aminopeptidase (map), translation initiation factor IF-1 (infA), and the RNA polymerase subunit alpha ( $r p o A)$. In $M$. synoviae, there is a cluster of 22 genes encoding ribo- 
somal proteins in a region of about $10 \mathrm{~kb}$. The block of genes secY-adk-map-infA-L36-S13-S11-rpoA-L17 is located in another region of the genome when compared to $M$. hyopneumoniae (Figure 1C). In addition, the L11 and L1 genes are not grouped in a separate cluster as in $M$. hyopneumoniae, E. coli and C. glutamicum (Figure 1C). The clusters "L10-L7/L2", "L13-S9" and "S12-S7-EF-G" of $M$. hyopneumoniae and M. synoviae are organized as in E. coli and C. glutamicum (Figure 1B). Figures $1 \mathrm{C}$ and 1D show particularities of the analyzed mycoplasma ribosomal protein clusters compared to E. coli and C. glutamicum. For example, the "L21-L27" gene cluster is absent in $M$. hyopneumoniae and present in E. coli and C. glutamicum in inverted position, as compared to M. synoviae (Figure 1C). Cluster "S16-TrmD-L19" is identical in the three mycoplasmas, while cluster "S4-L31" is specific to M. synoviae (Figure 1D). Neither cluster "S16-TrmD-L19" nor cluster "S4-L31" are present in E. coli or C. glutamicum.

\section{Organization and phylogenetic relationships among L33 ribosomal proteins}

Comparing the two M. hyopneumoniae strains, the organization of the ribosomal genes was identical, except for the L33 gene, of which strain 7448 presented two ORFs (MHP0638 and MHP0658) in different locations, while strain J presented only one (MHJ0658) (Table 1). The extra ORF in strain 7488 encodes a predicted protein of 46 amino acid residues, while the conserved ORF encodes a protein with 50 amino acid residues.

The phylogenetic relationships of the L33 ribosomal proteins were visualized by grouping into two big clades, A and B (Figure 2). Some mycoplasmas (M. pulmonis, M. pneumoniae M129, M. genitalium G37 and MP12668) presented two L33 genes. When present in duplicates, the orthologues were clustered in different clades, suggesting interphylum horizontal transfer and a possible specialized function to those proteins.

\section{Ribosomal RNAs}

In the $M$. synoviae genome, the $16 \mathrm{~S}$ rDNA is separated from the 23S rDNA by $259 \mathrm{bp}$, while in the $M$. hyopneumoniae strains the distance is about $490 \mathrm{bp}$ (data not shown). Downstream of the 23S rDNA, there is another spacer region followed by the $5 \mathrm{~S}$ rDNA gene. This region is located at a greater distance (about $100 \mathrm{~kb}$ ) than usual from the $16 \mathrm{~S}-23 \mathrm{~S}$ cluster. In M. pulmonis, for example, the $5 \mathrm{~S}$ gene is located $350 \mathrm{bp}$ distant from the genes encoding $16 \mathrm{~S}$ and 23S rRNAs (Chambaud et al., 2001). Those data confirm the previous observation that these sets of genes are localized in different regions of the $M$. hyopneumoniae genome (Taschke et al., 1986; Stemke et al., 1994). All mycoplasmas presented intervening tRNA genes, which seems to be common to all Mollicutes, except the phytoplasmas (Chambaud et al., 2001). In both $M$. hyopneumoniae strains only one set of $5 \mathrm{~S}, 16 \mathrm{~S}$ and $23 \mathrm{~S}$

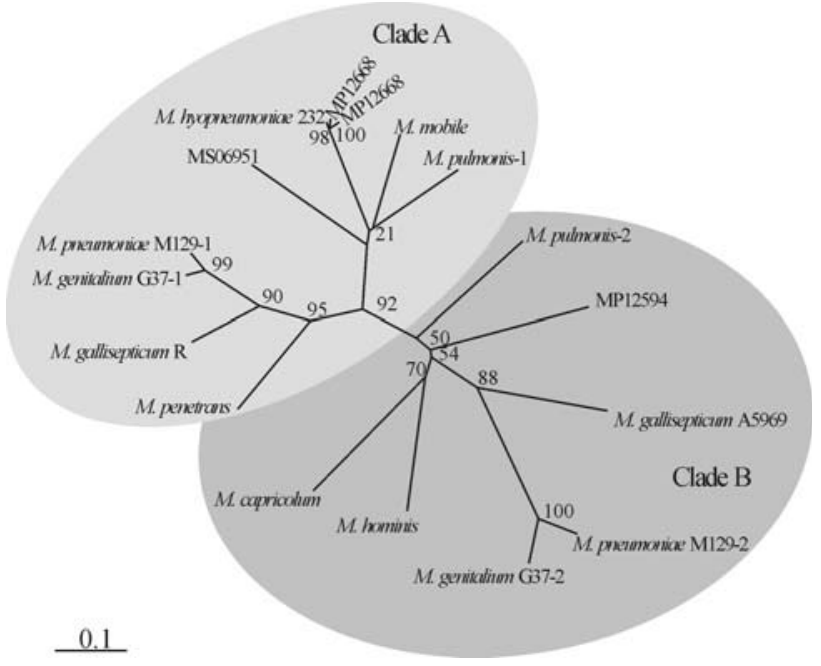

Figure 2 - Phylogenetic tree illustrating the relationships of L33 proteins. Sequences were aligned and subjected to phylogenetic analysis by using the minimum evolution (neighbor-joining) method. Numbers on branches indicate bootstrap values obtained for 100 replications. ORF identifications of M. synoviae, M. hyopneumoniae J, and M. hyopneumoniae 7448 are referred in Table 1, and the amino acid sequences are available at Mycoplasma databases. Other L33 protein sequences obtained were: $M$. capricolum (GenBank: Z33076_REGION: 279..440); M. gallisepticum A5969 (GenBank: L35043_REGION: 269..415); M. gallisepticum R (GenBank: AE016969_REGION: 9206..9367); M. genitalium G37-1 (GenBank: U39713.1:9938..10099); M. genitalium G37-2 (GenBank: U39684 L43967_REGION: 14657..14803); M. hominis (GenBank: AF443617_REGION: 2827..2976); M. hyopneumoniae 232 (GenBank: AE017332 REGION:856080..856232); M. mobile (GenBank: AE017308_REGION: 684469..684621); M. penetrans (GenBank: BA000026_REGION: 511349..511537); M. pneumoniae M129-1 (GenBank: AE000035 U00089_REGION: 3699..3860); M. pneumoniae M129-2 (GenBank: AE000010 U00089_REGION: 3699..3860); $M$. pulmonis-1 (GenBank: AL445563 REGION: 188281..188421); $M$. pulmonis-2 (GenBank: AL445564 REGION: 268039..268191).

rRNAs was identified. Two sets of $16 \mathrm{~S}$ and $23 \mathrm{~S}$ rRNA genes and three sets of 5S rRNA genes were identified in the $M$. synoviae genome.

\section{Translation initiation, elongation and termination}

The genes encoding initiation factors (IF-1, IF-2 and IF-3) are present in the genomes of $M$. synoviae and $M$. hyopmeumoniae $\mathrm{J}$ and 7448 . IF-1 is part of a cluster containing the genes which encode L36, S13, S11, rpoA and L17, among others (Figures $1 \mathrm{~A}$ and $1 \mathrm{C}$ ). In the two $M$. hyopneumoniae genomes, the gene encoding IF-2 is located between the genes coding for the ribosome-binding factor A $(r b f A)$ and the $\mathrm{N}$ utilization substance protein A (nusA). In M. synoviae, the gene is located between the genes encoding adenine phosphoribosyltransferase (apt) and nus $A$ (data not shown). The gene encoding IF-3 is part of a block of genes which encode the ribosomal proteins L35, L-20 and L28 in the genomes of both $M$. hyopneumoniae strains (Figure 1C). In M. synoviae, this gene is part of a block containing the genes which encode L35 and L20 (Figure 1C). 
The elongation factors EF-Ts, EF-Tu, EF-G and EF-P are present in the genomes of $M$. synoviae, $M$. hyopmeumoniae J, and M. hyopneumoniae 7448. As mentioned before, the gene encoding EF-G is part of the operon S12-S7-EF-G (Figure 1B). The gene encoding EF-Ts is located close to the gene encoding $\mathrm{S} 2$ in the genomes of both M. hyopneumoniae strains and of M. synoviae (data not shown).

The gene encoding the ribosome recycling factor ( $f r r$, which is responsible for the dissociation of the ribosomes from the mRNA after termination of translation, and is essential for bacterial growth (Janosi et al., 1996), is also present in the genomes of M. synoviae, M. hyopmeumoniae $\mathrm{J}$, and $M$. hyopneumoniae 7448 . Only one polypeptide release factor (prfA) was identified in both $M$. hyopneumoniae strains and in M. synoviae. This finding is consistent with the use of UAA and UAG as stop codons (Fraser et al., 1995; Himmelreich et al., 1996; Inagaki et al., 1996). Similar to the situation in other mycoplasma genomes, the UGA codon encodes tryptophan instead of stop codon. As a consequence, the peptide-chain release factor 2 (RF2), which recognizes the stop codons UGA and UAA, has become obsolete and was deleted, as proved experimentally in M. capricolum (Inagaki et al., 1993).

\section{Phylogenetic relationships among aminoacyl-tRNA synthetases}

Aminoacyl-tRNA synthetases catalyze the ligation of specific amino acids to their cognate tRNAs, which is the initial step in protein synthesis (Kim et al., 1993; Park et al., 2005). In the three sequenced genomes, $M$. hyopmeumoniae strains J and 7448 and $M$. synoviae, nineteen aminoacyl-tRNA synthetases were identified. Of the 20 standard tRNA-synthetases, glutaminyl-tRNA synthetase is the only one not detected in M. genitalium (Fraser et al., 1995) and M. pneumoniae (Himmelreich et al., 1996). In Bacillus subtilis, this problem is solved by charging the tRNA ${ }^{\text {Gln }}$ first with glutamate, which is subsequently converted to glutamine by an amidotransferase (Strauch et al., 1988). It has been shown that Glu-tRNA ${ }^{\text {Gln }}$ amidotransferase is a heterotrimeric enzyme encoded by the genes gatA, gatB, and gatC, which are part of an operon in $B$. subtilis (Curnow et al., 1997). In M. hyopneumonaie strain $\mathrm{J}$, the genes gatC (MH12539), gatA (MH15039), and gatB (MH21623) are organized in a cluster. The same kind of organization is observed in M. hyopneumoniae strain 7448 (gatC - MP09881, gatA - MP18574, gatB - MP12574). The organization of those genes in $M$. synoviae follows the order gatA - MS05589, gatB - MS05595, gatC - MS10482.

In order to analyze the grouping of the gat protein subunits, a phylogenetic tree was constructed and visualized, as shown in Figure 3. The deduced amino acid sequences of the ORFs encoding gat $\mathrm{A}$, gat $\mathrm{B}$ and gat $\mathrm{C}$ proteins of $M$. synoviae, $M$. hyopneumoniae $\mathrm{J}, M$. hyopneumoniae 7448 and complete sequences of other

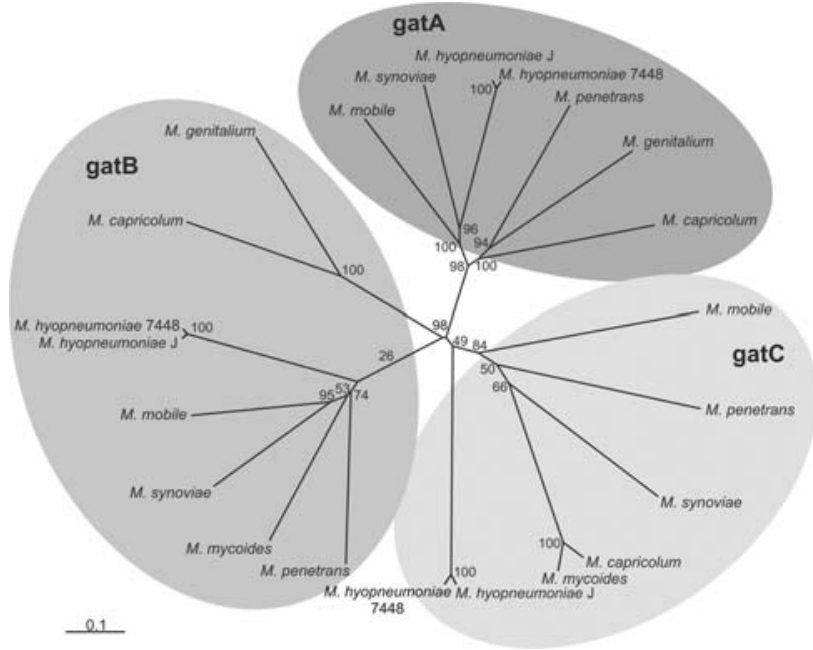

Figure 3 - Phylogenetic tree illustrating the relationships of gat A, B and C and related sequences. Phylogenetic analysis was based on the complete amino acid sequences of gat proteins. The tree was calculated by the neighbor-joining method implement in the program Clustal X, and drawn by using the TreeView program. The amino acid sequences are available at Mycoplasma databases. Gat protein sequences obtained from Mycoplasma databases were: $M$. capricolum (GenBank: YP_424670; YP_424122; YP_424671); M. genitalium (GenBank: AAC71317; AAC $\bar{A} 2482)$; M. hyopneumoniae J (GenBank: AAZ44118; AAZ44119; AAZ44117); $M$. hyopneumoniae 7448 (GenBank: AAZ53405; AAZ53406; AAZ53404); M. mobile (GenBank: AAT27863; AAT27862; AAT27864); M. mycoides (GenBank: CAE77379; CAE77381); $M$. penetrans (GenBank: BAC44001; BAC44002; BAC44000); M. synoviae (GenBank: AAZ43513.1; AAZ43512.1; AAZ43514).

mycoplasma proteins from databases were aligned. The bootstrap values (98\%) among gat A, gat B and gatC indicate the high identity among the gat groups of the mycoplasmas. In Figure 3, separated clades comprising gatA, gatB and gat $C$ can be observed. Only one gat protein subunit has been described for each mycoplasma. A higher identity was found between gatA (97\%), gatB (94\%), and gatC $(96 \%)$ of $M$. hyopneumoniae 7448 and $M$. hyopneumoniae J (data not shown) when compared to other mycoplasmas and formed single groups inside the clades. This observation suggests a common ancestral.

\section{Acknowledgments}

This work was performed by the Brazilian National Genome Program (Southern Network for Genome Analysis and Brazilian National Genome Project Consortium) with funding provided by $\mathrm{MCT} / \mathrm{CNPq}$ and SCT/FAPERGS (RS).

\section{References}

Altschul SF, Madden TL, Schaffer AA, Zhang J, Zhang Z, Miller W and Lipman DJ (1997) Gapped BLAST and PSI-BLAST: A new generation of protein database search programs. Nucleic Acids Res 25:3389-3402.

Bencina D, Narat M, Dove P, Drobnic-Valic M, Habe F and Kleven SH (1999) The characterization of Mycoplasma 
synoviae EF-Tu protein and proteins involved in hemadherence and their N-terminal amino acid sequences. FEMS Microbiol Lett 173:85-94.

Cerretti DP, Dean D, Davis GR, Bedwell DM and Nomura M (1983) The spc ribosomal protein operon of Escherichia coli: Sequence and cotranscription of the ribosomal protein genes and a protein export gene. Nucleic Acids Res 11:2599-2616.

Chambaud I, Heilig R, Ferris S, Barbe V, Samson D, Galisson F, Moszer I, Dybvig K, Wroblewski H, Viari A, et al. (2001) The complete genome sequence of the murine respiratory pathogen Mycoplasma pulmonis. Nucleic Acids Res 29:2145-2153.

Curnow AW, Hong K, Yuan R, Kim S, Martins O, Winkler W, Henkin TM and Soll D (1997) Glu-tRNAGln amidotransferase: A novel heterotrimeric enzyme required for correct decoding of glutamine codons during translation. Proc Natl Acad Sci USA 94:11819-11826.

Fraser CM, Gocayne JD, White O, Adams MD, Clayton RA, Fleischmann RD, Bult CJ, Kerlavage AR, Sutton G, Kelley JM, et al. (1995) The minimal gene complement of Mycoplasma genitalium. Science 270:397-403.

Held WA, Ballou B, Mizushima S and Nomura M (1974) Assembly mapping of $30 \mathrm{~S}$ ribosomal proteins from Escherichia coli. Further studies. J Biol Chem 249:3103-3111.

Himmelreich R, Hilbert H, Plagens H, Pirkl E, Li BC and Herrmann R (1996) Complete sequence analysis of the genome of the bacterium Mycoplasma pneumoniae. Nucleic Acids Res 24:4420-4449.

Inagaki Y, Bessho Y and Osawa S (1993) Lack of peptide-release activity responding to codon UGA in Mycoplasma capricolum. Nucleic Acids Res 21:1335-1338.

Inagaki Y, Bessho Y, Hori H and Osawa S (1996) Cloning of the Mycoplasma capricolum gene encoding peptide-chain release factor. Gene 169:101-103.

Janosi L, Hara H, Zhang S and Kaji A (1996) Ribosome recycling by ribosome recycling factor (RRF) - an important but overlooked step of protein biosynthesis. Adv Biophys 32:121201.

Jordan FT (1981) Mycoplasma-induced arthritis in poultry. Isr J Med Sci 17:622-625.

Kim S, Landro JA, Gale AJ and Schimmel P (1993) C-terminal peptide appendix in a class I tRNA synthetase needed for acceptor-helix contacts and microhelix aminoacylation. Biochemistry 32:13026-13031.

Kobisch M (2000) Mycoplasma diseases in pigs - Old diseases still causing trouble. In: Proceedings $16^{\text {th }}$ International Pig Veterinary Society Congress: 434-438, Melbourne, Australia.

Kobisch M and Friis NF (1996) Swine mycoplasmoses. Révue Scientifique et Technique de 1'Office International de Epizooties 15:1569-1605.

Lafontaine DL and Tollervey D (2001) The function and synthesis of ribosomes. Nat Rev Mol Cell Biol 2:514-520.

Lecompte O, Ripp R, Thierry JC, Moras D and Poch O (2002) Comparative analysis of ribosomal proteins in complete genomes: An example of reductive evolution at the domain scale. Nucleic Acids Res 30:5382-5390.

Maniloff J (1996) The minimal gene genome: "On being the right size”. Proc Natl Acad Sci USA 93:10004-10006.
Martín JF, Barreiro C, Gonzalez-Lavado E and Barriuso M (2003) Ribosomal RNA and ribosomal proteins in corynebacteria. J Biotechnol 104:41-53.

Park SG, Ewalt KL and Kim S (2005) Functional expansion of aminoacyl-tRNA synthetases and their interacting factors: New perspectives on housekeepers. Trends Biochem Sci 30:569-574.

Razin S (1992) Mycoplasma taxonomy and ecology. In: Maniloff J, McElhaney RN, Finch LR and Baseman JB (eds) Mycoplasmas: Molecular Biology and Pathogenesis. Am Soc Microbiol, Washington, DC, pp 3-22.

Rohl R and Nierhaus KH (1982) Assembly map of the large subunit (50S) of Escherichia coli ribosomes. Proc Natl Acad Sci USA 79:729-733.

Saitou N and Nei M (1987) The neighbor-joining method: A new method for reconstructing phylogenetic trees. Mol Biol Evol 4:406-425.

Stemke GW, Huang Y, Laigret F and Bove JM (1994) Cloning the ribosomal RNA operons of Mycoplasma flocculare and comparison with those of Mycoplasma hyopneumoniae. Microbiology 140:857-860.

Stern S, Powers T, Changchien LM and Noller HF (1988) Interaction of ribosomal proteins S5, S6, S11, S12, S18 and S21 with 16 S rRNA. J Mol Biol 201:683-695.

Strauch MA, Zalkin H and Aronson AI (1988) Characterization of the glutamyl-tRNA(Gln)-to-glutaminyl-tRNA(Gln) amidotransferase reaction of Bacillus subtilis. $\mathrm{J}$ Bacteriol 170:916-920.

Taschke C, Klinkert MQ, Wolters J and Herrmann R (1986) Organization of the ribosomal RNA genes in Mycoplasma hyopneumoniae: The 5S rRNA gene is separated from the 16S and 23S rRNA genes. Mol Gen Genet 205:428-433.

Thompson JD, Gibson TJ, Plewniak F, Jeanmougin F and Higgins DG (1997) The CLUSTAL X windows interface: Flexible strategies for multiple sequence alignment aided by quality analysis tools. Nucleic Acids Res 25:4876-4882.

Uchiumi T, Honma S, Nomura T, Dabbs ER and Hachimori A (2002) Translation elongation by a hybrid ribosome in which proteins at the GTPase center of the Escherichia coli ribosome are replaced with rat counterparts. J Biol Chem 277:3857-3862.

Vasconcelos AT, Ferreira HB, Bizarro CV, Bonatto SL, Carvalho MO, Pinto PM, Almeida DF, Almeida LG, Almeida R, Alves-Filho L, et al. (2005) Swine and poultry pathogens: The complete genome sequences of two strains of Mycoplasma hyopneumoniae and a strain of Mycoplasma synoviae. J Bacteriol 187:5568-5577.

Voet D and Voet JG (1992) Ribosomas. In: Bioquímica. Ediciones Omega S.A., Barcelona, pp 979-982.

Yusupov MM, Yusupova GZ, Baucom A, Lieberman K, Earnest TN, Cate JH and Noller HF (2001) Crystal structure of the ribosome at 5.5 A resolution. Science 292:883-896.

\section{Internet Resources}

M. synoviae complete genome database, http://www.brgene.lncc. br/finalMS/.

M. hyopneumoniae strain J and M. hyopneumoniae strain 7448 complete genome databases, http://www.genesul.lncc.br.

BLAST tools, http://www.ncbi.nlm.nih.gov/BLAST/. Associate Editor: Arnaldo Zaha 